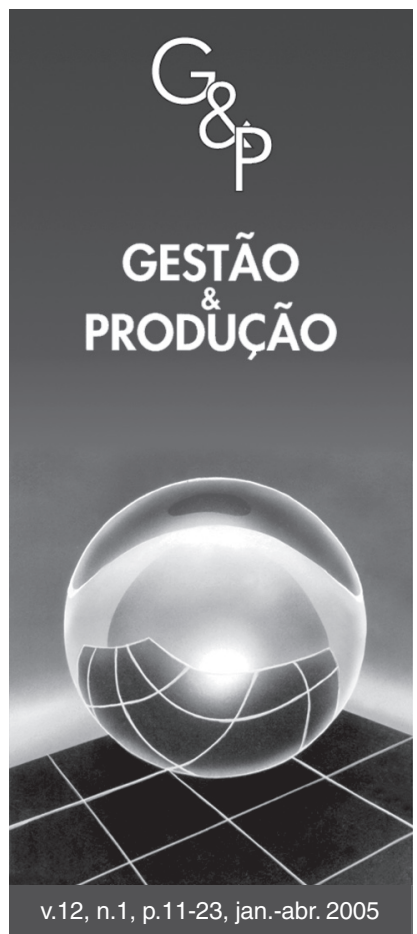

\title{
ENTENDENDO O FUTEBOL COMO UM NEGÓCIO: UM ESTUDO EXPLORATÓRIO
}

\author{
Marvio Pereira Leoncini \\ Curso de Graduação em Educação Física, \\ Faculdades Integradas Stella Maris Andradina, \\ Rua Amazonas, 571, CEP 16901-160, Andradina, SP, \\ e-mail: leoncini@usp.br; marvio.pereira@itelefonica.com.br
}

Márcia Terra da Silva

Departamento de Engenharia de Produção, Escola Politécnica da USP, Av. Prof. Almeida Prado, 128, trav. 2, Edifício José Otávio Monteiro de Camargo, CEP 05508-070, Cidade Universitária, São Paulo, SP, e-mail: mtdsilva@usp.br

Recebido em 04/9/2003 Aceito em 08/12/2004

Resumo

Este trabalho de natureza exploratória trata do desenvolvimento de um modelo de análise que explique o processo de profissionalização na gestão de clubes de futebol. O modelo de análise não contempla variáveis políticas que são uma parte importante do âmbito de atuação dos clubes, contudo está pautado nos conceitos de aprendizagem sistêmica, usados para compreender as mudanças organizacionais. Como contribuição teórica, o modelo aponta as principais características estruturais da indústria do futebol, além de indicar alguns princípios de gestão aplicáveis aos clubes como empresas de serviços. Ao final, a comparação do modelo desenvolvido com dois estudos de caso tem como objetivos básicos a identificação de princípios de gestão já interiorizados nos clubes pesquisados e o teste da coerência interna do modelo.

Palavras-chave: futebol, cadeia de valor, mudança organizacional, estratégia de operações, administração de serviços.

\section{Introdução}

O futebol mundial é hoje um grande negócio. De acordo com o relatório final do Plano de Modernização do Futebol Brasileiro (2000) da Fundação Getúlio Vargas (FGV), que inclui os agentes diretos, como clubes e federações, e indiretos, como indústrias de equipamentos esportivos e a mídia, o futebol mundial movimenta, em média, cerca de 250 bilhões de dólares anuais. No Brasil, dados desse mesmo relatório mostram que o futebol é uma atividade econômica com grande capacidade de gerar empregos, e tem efeito multiplicador maior que vários setores tradicionais, contabilizando:

- trezentos (300) mil empregos diretos;

- trinta (30) milhões de praticantes (formais e não formais);

- quinhentos e oitenta (580) mil participantes em treze (13) mil times que participam de jogos organizados (esporte formal);
- quinhentos e oitenta (580) estádios com capacidade para abrigar mais de cinco e meio $(5,5)$ milhões de torcedores;

- cerca de quinhentos (500) clubes profissionais disputando uma média de noventa (90) partidas por ano; e

- em termos de fornecimento anual de materiais e equipamentos esportivos, são cerca de nove (9) milhões de chuteiras para futebol e futsal, seis (6) milhões de bolas e trinta e dois (32) milhões de camisas.

Mesmo assim, o Brasil está longe de aproveitar todo seu potencial. Comparado ao valor mundial citado acima, o futebol brasileiro representa menos de $1 \%$ dos duzentos e cinqüenta (250) bilhões de dólares movimentados anualmente. Além dos problemas estruturais da nossa economia e das diferenças de renda per capita entre o Brasil e os principais países que investem no futebol como atividade econômica (por exemplo, Espanha, Ale- 
manha, Itália e Inglaterra), a administração dos dirigentes tradicionais de clubes e federações de futebol tem sido apontada como a causa mor que faz com que o futebol brasileiro não consiga aproveitar plenamente seu potencial econômico, principalmente nos chamados agentes diretos - clubes e federações. De acordo com o Jornal Gazeta Mercantil (quinta-feira, 14 de Outubro de 1999), o valor potencial dos clubes de futebol no Brasil poderia ser estimado como se segue:

- Valor do time depende principalmente do número de torcedores;

- Para estimar quanto, em média, cada torcedor gasta anualmente com futebol no Brasil, a média de gasto do torcedor inglês foi adotada como padrão ideal. Tal média foi então ajustada proporcionalmente aos valores do PIB per Capita de cada país (Inglaterra R \$ 36.260/Brasil $\mathrm{R} \$ 5.781=15,9 \%$ ), o que resultou numa média ajustada de gastos anuais com futebol no Brasil de $\mathrm{R} \$ 57$ ou US $\$ 20$ por torcedor (1 dólar = R \$ 3,00 atualmente); e

- Logo, o valor comercial estimado de cada time é calculado multiplicando-se o número de seus torcedores por US\$20.

Assim, o Corinthians, com cerca de 17 milhões de torcedores, teria um potencial de geração de renda de apro- ximadamente US\$ 340 milhões por ano, e o Flamengo, com cerca de 25 milhões de torcedores, valeria aproximadamente US $\$ 500$ milhões, admitindo-se sempre uma exploração comercial do futebol nos moldes ingleses. No entanto, o balanço dos principais clubes brasileiros publicados em 2003 (Tabela 1) mostra que tais potenciais de geração de receita, ao menos oficialmente, estão muito longe de se tornarem realidade. Só para se ter uma idéia da ordem de grandeza, o Flamengo faturou oficialmente em 2002 R \$ 67,7 milhões, o que significou quase US\$ 23 milhões ( 1 dólar $=3$ reais), ou 4,6\% do seu potencial. Já o Corinthians faturou apenas $\mathrm{R} \$ 17,4$ milhões, o que significou quase US\$ 6 milhões, ou 1,8\% do seu potencial.

Por que no Brasil o futebol não gera resultados econômicos compatíveis com seus resultados esportivos? Faltaria aos clubes e ligas uma gestão profissional para melhorar seu desempenho econômico? Como colocam Motta e Pereira (1980), o termo profissional surge com a Escola de Administração Clássica, no contexto da racionalização do trabalho e da organização burocrática. Em tais organizações burocráticas "puras", os administradores profissionais dirigem a organização de forma estritamente racional, impessoal, sem ódio ou paixão. Essa característica da impessoalidade burocrática, da busca da consecução dos objetivos pré-definidos da forma mais

Tabela 1. Resumo da Demonstração de Resultado Financeiro dos principais clubes brasileiros em 2002 (Fonte: Jornal Lance!A+ (2003) “Acerto de Contas", artigo assinado por Alex Sabino).

\begin{tabular}{|c|c|c|c|c|c|c|c|c|c|c|}
\hline $\begin{array}{c}2002 \text { (em } \\
\text { R\$ milhões) }\end{array}$ & $\begin{array}{c}\text { Atlético- } \\
\text { MG }\end{array}$ & $\begin{array}{l}\text { Corin- } \\
\text { thians }\end{array}$ & Cruzeiro & Flamengo & Fluminense & Grêmio & Palmeiras & Santos & $\begin{array}{c}\text { São } \\
\text { Paulo }\end{array}$ & $\begin{array}{l}\text { Total de } \\
\text { dívidas }\end{array}$ \\
\hline Receita & 50,4 & 17,4 & 41,0 & 67,7 & 27,3 & 28,2 & 45,8 & 24,8 & 77,0 & \multirow{9}{*}{$\begin{array}{c}851,1 \\
\text { milhões de } \\
\text { reais }\end{array}$} \\
\hline Despesa & 53,7 & 36,6 & 40,3 & 106,3 & 49,8 & 56,4 & 61,8 & 38,0 & 90,0 & \\
\hline Déficit/Superávit* & $-3,3$ & $-19,1$ & 0,6 & $-38,7$ & $-22,4$ & $-28,1$ & $-16,0$ & $-13,2$ & $-13,0$ & \\
\hline $\begin{array}{l}\text { Dívida a curto } \\
\text { prazo }\end{array}$ & 54,8 & 28,4 & 7,0 & 88,2 & 75,9 & 56,5 & 9,1 & 35,5 & 14,8 & \\
\hline $\begin{array}{l}\text { Dívida a longo } \\
\text { prazo }\end{array}$ & 43,2 & 0,5 & 50,7 & 118,5 & 40,0 & 39,7 & 110,6 & 53,4 & 24,3 & \\
\hline Dívida Total & 98,0 & 28,9 & 57,7 & 206,7 & 115,9 & 96,2 & 119,7 & 88,9 & 39,1 & \\
\hline $\begin{array}{l}\text { Variação da Dívi- } \\
\text { da** }\end{array}$ & $5,0 \%$ & $-15,5 \%$ & $13,8 \%$ & $30,8 \%$ & $23,0 \%$ & $11,7 \%$ & $-0,16 \%$ & $19,1 \%$ & $237,0 \%$ & \\
\hline $\begin{array}{l}\text { Patrimônio Liqui- } \\
\text { do*** }\end{array}$ & $-88,5$ & 56,1 & 49,1 & $-113,2$ & $-79,5$ & 15,5 & 151,2 & 94,9 & 111,8 & \\
\hline $\begin{array}{l}\text { Superávit/Déficit } \\
\text { no exercício**** }\end{array}$ & $-3,3$ & $-13,2$ & 0,3 & $-38,7$ & $-22,4$ & $-18,0$ & $-11,7$ & 34,7 & $-22,8$ & \\
\hline Observações***** & $\begin{array}{l}\text { Dívidas de } \\
\text { curto prazo } \\
\text { bem acima } \\
\text { do dispo- } \\
\text { nível para } \\
\text { pagar }\end{array}$ & $\begin{array}{l}\text { É a menor } \\
\text { dívida entre } \\
\text { os grandes } \\
\text { clubes }\end{array}$ & $\begin{array}{l}\text { Teve } \\
\text { redução } \\
\text { signifi- } \\
\text { cativa de } \\
\text { receita }\end{array}$ & $\begin{array}{l}\text { Aumentou } \\
\text { ainda mais a } \\
\text { dívida com } \\
\text { grande déficit } \\
\text { de } 2002\end{array}$ & $\begin{array}{l}\text { Pouco dinhei- } \\
\text { ro para pagar } \\
\text { as dívidas de } \\
\text { curto prazo }\end{array}$ & $\begin{array}{l}\text { Não } \\
\text { conseguiu } \\
\text { reduzir as } \\
\text { despesas } \\
\text { mesmo } \\
\text { com a saída } \\
\text { da ISL }\end{array}$ & $\begin{array}{l}\text { Déficit } \\
\text { multiplicado } \\
\text { por 30. Deve } \\
\text { mais de } \\
\text { R\$ } 100 \text { mi- } \\
\text { lhões à } \\
\text { Palmeiras } \\
\text { S/A }\end{array}$ & $\begin{array}{l}\text { Contabi- } \\
\text { lizou os } \\
\text { "passes" } \\
\text { como } \\
\text { receita, } \\
\text { o que } \\
\text { explica o } \\
\text { superávit }\end{array}$ & $\begin{array}{l}\text { Sua } \\
\text { dívida } \\
\text { mais que } \\
\text { triplicou }\end{array}$ & $\begin{array}{l}\text { Os nove } \\
\text { grandes } \\
\text { clubes que } \\
\text { publicaram } \\
\text { suas contas } \\
\text { têm a dívida } \\
\text { colossal } \\
\text { de quase } \\
\text { R } \$ 1 \text { bilhão }\end{array}$ \\
\hline
\end{tabular}

\footnotetext{
* Receita menos despesa

** Em redução a dívida de 2001

*** Total de ativos do clube menos sua dívida

**** Receita menos despesa; incluindo variação do patrimônio e das dívidas anteriores

***** Entre os 12 grandes clubes, Botafogo, Internacional e Vasco não publicaram seus balanços
} 
econômica e eficiente possível, se contrapõe ao tradicional caráter amador e de abnegação na gestão do futebol, em que a paixão pela camisa do clube ou raiva do time adversário pode obscurecer as decisões tomadas.

Como agregar à análise administrativa estas questões próprias do negócio futebol? Este trabalho propõe analisar o setor como um sistema de produção em que se agregam aspectos próprios das organizações de futebol profissional, como a importância da conquista de sucesso esportivo (ganhar jogos, títulos de competições, etc.), que está inscrita na própria natureza de tais instituições e que se configura como um dos elementos mais importantes para a satisfação dos clientes-torcedores.

Neste nosso enfoque, as variáveis políticas tanto internas à indústria de futebol, como à estrutura do poder nas organizações esportivas, quanto externas, como as relações destas com o ambiente social e institucional, não são analisadas. Contudo, são variáveis importantes para explicar como surge a necessidade de mudança e de profissionalização dos dirigentes de clubes e federações de futebol. Por exemplo, com recorrência, várias questões relacionadas com tais variáveis são elevadas à condição de destaque como tema de interesse público estampado na imprensa escrita e falada. Dentre elas, o descaso com o cliente-torcedor caracterizado pela violência nos estádios, o excesso de negociações dos melhores jogadores para a Europa, em que o interesse de alguns prevalece sobre o interesse de muitos, às vezes por vias ilegais, as manobras políticas de dirigentes de federações mudando regras de acesso e descenso entre divisões dos campeonatos nacionais de futebol, etc. Todas essas ações representam políticas administrativas ou posicionamentos estratégicos tidos como equivocados e que, ao mesmo tempo, dificultam a mudança de comando no poder de clubes e federações e desvalorizam o potencial de geração de renda dessa indústria.

Esse anacronismo de posicionamento estratégico dos clubes frente à evolução do negócio futebol mostra que, assim como as organizações industriais, também os clubes e as federações de futebol precisam se adequar a mudanças do ambiente para poderem sobreviver a longo prazo. Os problemas do futebol brasileiro citados anteriormente deram origem a inúmeras mudanças na Legislação Esportiva (Lei Pelé em 1998, Nova Lei Pelé em 2001 e 2003, Estatuto do Torcedor em 2003), todas buscando equacionar tais problemas pela via político-institucional. Além disso, a grande maioria dos clubes de futebol apresenta problemas de eficiência financeira, como mostra a Tabela 1. Tais forças econômicas e políticas empurram os clubes e federações de futebol rumo à profissionalização e à mudança de posicionamento estratégico. No entanto, como se adequar às mudanças do ambiente sem sequer saber que ambiente é este?

Neste trabalho partiremos do pressuposto de que para qualquer agente da indústria de futebol se posicionar como agente econômico, é necessário um entendimento preliminar das características estruturais e dinâmicas de tal indústria. Neste sentido, as seguintes questões de pesquisa norteiam nosso trabalho:

- O futebol é um sistema de produção? Quem são seus clientes? Quais são seus insumos? Qual o processo de produção?

- Qual o papel dos clubes e das federações?

- O que significa sucesso nessa indústria? Quais os fatores que os explicam?

- Existem diferenças de estratégias de negócios entre os vários clubes no Brasil e no Mundo? Como diferentes estratégias implicam diferentes operações de negócio?

Os trabalhos que tratam do tema futebol como negócio no Brasil, além de escassos, na sua maioria relatam experiências profissionais e opiniões de dirigentes esportivos. Fora do país, na sua grande maioria, os livros científicos tratam do esporte como negócio de forma geral, e os livros sobre gestão do futebol se concentram no país que criou o futebol moderno, e hoje é exemplo de profissionalismo na direção deste esporte, a Inglaterra.

É neste contexto que surgem cursos de especialização em escolas de administração com o intuito de suprir a carência de conhecimento pela transmissão de conceitos administrativos aos atuais e futuros gestores da indústria do esporte e do futebol. Além disso, as parcerias entre empresas investidoras e clubes, que se verificaram no Brasil nos últimos tempos, sinalizam a necessidade de novas perspectivas de gestão para o negócio futebol. Assim, este trabalho, a partir de uma abordagem exploratória, busca tornar mais claro o negócio futebol como um sistema de produção para os clubes.

Para isto, este trabalho buscou aplicar conceitos clássicos de análise estratégica de indústrias com o foco na análise do processo de mudança presente na história recente dos clubes de futebol. Nesse período de mudança, as estruturas e dinâmicas de produção questionadas são e podem ser mais facilmente reconhecidas.

A metodologia utilizada se baseou nos preceitos oriundos do estudo de caso, já que se trata de tema pouco explorado cientificamente e o objetivo central de pesquisa é antes exploratório/descritivo do que o de comprovar hipóteses de pesquisa, conforme Yin (1994). Aproveitandose da possibilidade de se utilizarem múltiplas fontes de informação, foram utilizadas tanto a pesquisa bibliográfica em fontes primárias (documentos internos, jornais e revistas especializadas em futebol) e secundárias (livros e textos científicos sobre gestão e produção) quanto entrevistas semi-estruturadas com pessoas-chave envolvidas no processo de parceria de dois clubes brasileiros com empresas.

As entrevistas semi-estruturadas foram realizadas no ano de 2000, com dirigentes e parceiros de dois clubes 
brasileiros, Flamengo e São Caetano, escolhidos como casos típicos de estratégias operacionais distintas. No caso do Flamengo, a entrevista foi usada como a principal fonte de informação (no entanto, uma fita de vídeo, usada durante a apresentação da proposta de parceria perante o Conselho Deliberativo do Clube, também é uma fonte de informação documental importante). A entrevista foi agendada com o diretor da Pelé Sports \& Marketing (PS\&M - que foi a empresa que intermediou a parceria entre o Clube e o Investidor). No caso do São Caetano, foram agendadas e conduzidas entrevistas com o Presidente em exercício e o Gerente Administrativo do Clube. As entrevistas foram usadas como as principais fontes de informação. Outras fontes, como cópias dos contratos e boletins informativos também foram usadas como fontes alternativas.

\section{O processo de mudança na gestão de clubes como referencial teórico para o entendimento do negócio futebol}

De acordo com Edward Freedman (in: Jornal Administrador Profissional, Ano XXVII - $\mathrm{n}^{\circ}$. 213, Março de 2004), o responsável pelo marketing do Manchester United da Inglaterra, "os clubes brasileiros precisam de profissionais especializados, que entendam o mercado e saibam otimizar as oportunidades comerciais". Além disso, Freedman disse que, embora a prática do esporte seja a função principal de um clube, é preciso que as áreas administrativas sejam consideradas partes da estrutura esportiva, para poder gerar receitas com o sucesso do time.

As declarações de Freedman poderiam ter sido feitas em meados dos anos 90, no início do processo de mudança ocorrido no âmago da indústria do futebol brasileiro, por meio do estabelecimento dos contratos de parceria entre clubes e empresas para a gestão comercial dos clubes. No entanto, ela ocorre cerca de três anos após a maioria dos contratos já terem sido desfeitos, antes mesmo de seu término. Fazem parte deste universo, empresas que aportaram recursos nos clubes com os mais variados interesses. Desde empresas especializadas em marketing esportivo ou envolvidas com investimentos no setor de mídia e entretenimento, como as parcerias entre Corinthians e Hicks Muse Tate \& Furst e entre Flamengo e a International Sports Leisure (ISL), até empresas interessadas em atuar no mercado de compra e venda de jogadores, como as parcerias entre a A. D. São Caetano e a Datha Representações e até mesmo entre Palmeiras e Parmalat (apesar dos objetivos de marketing esportivo serem os motivadores desta parceria pelo lado da empresa).

Assim, a década de 90 assistiu a uma série de mudanças na administração do futebol, pelo estabelecimento de contratos de parceria entre clubes e empresas para a gestão comercial dos clubes. A maioria dessas parcerias foi desfeita antes do término do contrato. Essas mudanças foram motivadas por certas percepções sobre o potencial do futebol como negócio, dentro de uma racionalidade que chamamos de econômica. As razões para o término das parcerias, motivadas por interesses diversos, não são objeto deste trabalho, mas sim o entendimento dos princípios econômicos que nortearam as parcerias e expuseram os clubes de futebol como empresas e seus negócios como sistemas de produção.

Segundo Fleury e Fleury (2000), para compreender o processo de mudanças por que passam as empresas, três percepções conceituais devem ser observadas:

- a primeira implica ultrapassar uma visão estática da realidade, assumindo o movimento dos processos em curso, por meio da identificação dos principais atores envolvidos (caracterização da cadeia produtiva, suas interfaces e mecanismos de coordenação), seus objetivos (propósitos fundamentais), processos de interação (características gerais do processo produtivo e fatores e funções críticas para a competitividade) e indicadores de desempenho; este tipo de caracterização fornece uma visão clara da estrutura da indústria e do negócio;

- a segunda implica trabalhar o conceito de competência associado à estratégia empresarial. Nesse raciocínio, a empresa, situada em um arranjo produtivo qualquer, define sua estratégia e as competências necessárias para implementá-la num processo de aprendizagem permanente que é antes um círculo virtuoso que uma hierarquia de mão única; e

- a terceira implica adotar uma abordagem sistêmica com relação às dinâmicas decorrentes de tal processo de aprendizagem, conforme Fleury e Fleury (2000, p. 41): "o processo de aprendizagem que cada empresa estrutura...... gera dinâmicas de mudança internas à empresa, entre as empresas e entre grupos de empresas".

O objeto de análise para a aplicação dos conceitos acima é o processo de mudança na gestão do clube e sua inserção na indústria do futebol. Tal foco de análise pode ser caracterizado e definido por meio da noção de ciclos permanentes de aprendizagem e mudança nas diferentes atividades empresariais de tal indústria, ilustrados na Figura 1.

As mudanças ou dinâmicas interempresariais são dinâmicas internas à indústria do futebol que podem ser decorrentes de mudanças horizontais ou verticais. As mudanças horizontais implicam criação de novas relações interempresariais que buscam otimizar a participação das organizações em mercados existentes ou potenciais, principalmente pela complementaridade de competências, de acordo com suas estratégias a longo prazo: o licenciamento da marca de um clube para um novo agente tem como finalidade aumentar a participação da "nova empresa" no mercado de torcedores, criando e agregando novos conceitos de produtos e serviços ao mercado de 
torcedores. As mudanças verticais implicam a criação de novas relações interempresariais que buscam reestruturar a cadeia ou indústria, tendo em vista torná-la mais eficiente: como a criação de parcerias com empresas de venda de ingressos pela internet, que buscam otimizar a distribuição dos ingressos.

As aprendizagens estratégica e organizacional determinam o modelo de gestão adotado por uma organização num determinado momento. Nesta abordagem, tais aprendizagens, apesar da sua natureza dinâmica, são percebidas como visões de negócio e competências já interiorizadas pela organização ou pelos seus dirigentes.

No caso do processo de mudança do modelo de gestão do Flamengo, duas dinâmicas complementares puderam ser observadas: a ineficácia do modelo de gestão adotado até então pelo clube e a solução adotada pela diretoria para enfrentar tal ineficácia. A ineficácia do modelo de gestão do clube pôde ser medida pelos seus desempenhos esportivo (sem conquistas importantes nos últimos anos) e financeiro (com uma dívida estimada em $\mathrm{R} \$ 80$ milhões no ano de 2000). A solução adotada foi a assinatura de um

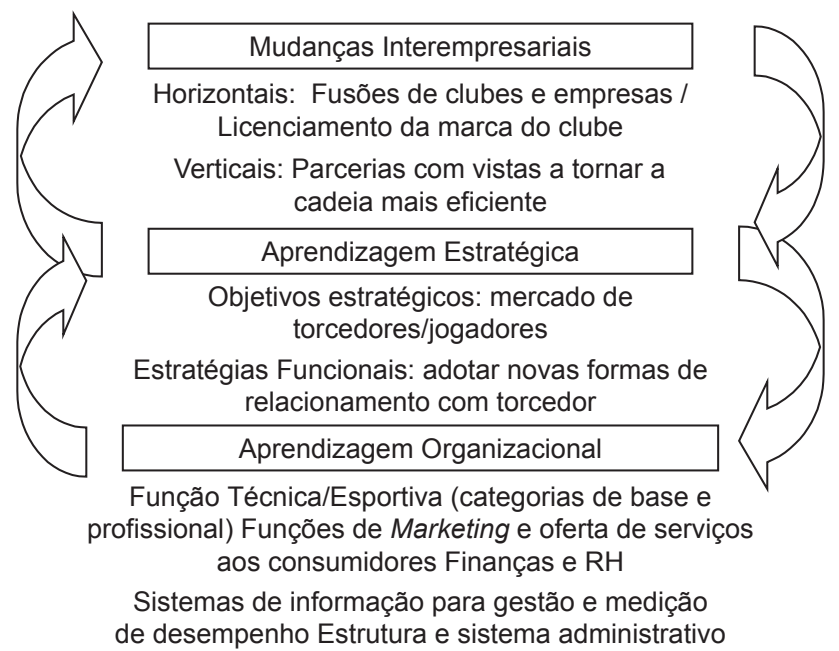

Figura 1. Ciclos permanentes de aprendizagem e mudança para a análise do processo de mudança na gestão de clubes de futebol (Fonte: Leoncini, 2001). contrato de licenciamento de marca, um modelo típico de complementaridade de competências entre o Flamengo (competência para gerir o departamento técnico) e a ISL (competência para gerir o departamento de Marketing do Flamengo) para tornar o negócio futebol mais eficiente e lucrativo, agregando o lucro aos objetivos estratégicos da nova organização resultante. No momento da pesquisa de campo a parceria ainda era incipiente, já que havia sido efetivada há poucos meses.

No caso do São Caetano, tais dinâmicas se resumem à entrada de uma nova empresa (Datha Representações) para gerir o negócio futebol do clube em forma de cogestão, motivada principalmente pela vontade política de seus dirigentes de tornar o clube vitorioso nacionalmente com uma gestão responsável e profissional. Novamente, aqui se observa a complementaridade de competências para gerir o negócio futebol: a Datha participa da gestão do departamento técnico de futebol (opinando sobre decisões importantes e tendo o controle sobre tais operações) e atua na captação de recursos por meio do Marketing Esportivo (venda de placas de propaganda nos estádios, patrocínio na camisa, etc.) para melhorar as receitas do clube. No momento da pesquisa de campo a parceria já operava e começava a mostrar seus resultados de 4 anos de existência (ver Tabela 2).

Entender então o processo de mudança na gestão dos clubes de futebol passa pelo entendimento das condicionantes estruturais (as características da estrutura da indústria e do negócio futebol) e dinâmicas (as mudanças interempresariais) que os permeiam e que afetam o processo de aprendizagem que envolve a concepção de um modelo de gestão estratégica, este entendido como um conjunto de competências organizacionais (políticas, princípios de gestão e funções) interiorizados na organização e que são derivados de uma visão estratégica.

\section{A estrutura da indústria de futebol}

Do ponto de vista econômico, os mercados produtores e consumidores de espetáculos esportivos sofreram gran-

Tabela 2. Os resultados esportivos e financeiros da A. D. São Caetano de 1995 a 2000 (Fonte: Aidar et al., 2000).

\begin{tabular}{ccccccc}
\hline Ano & $\begin{array}{c}\text { Receitas Totais } \\
\text { Líquidas em R\$ } \\
\text { Milhares }\end{array}$ & Despesas Totais & \multicolumn{4}{c}{ Desempenho Esportivo } \\
em R\$ Milhares & \multicolumn{2}{c}{ Campeonato Paulista } & \multicolumn{2}{c}{ Campeonato Brasileiro } \\
Divisão & Posição \\
\hline 1995 & 870,00 & 900,00 & A3 & 10 & $* *$ & $* *$ \\
1996 & $2.280,00$ & $2.230,00$ & A3 & 11 & $* *$ & $* *$ \\
1997 & $1.660,00$ & $1.730,00$ & A3 & 4 & $* *$ & 2 \\
1998 & 710,00 & 690,00 & A3 & 1 & C & 2 \\
1999 & $2.310,00$ & $2.290,00$ & A2 & 4 & B & 5 \\
2000 & $*$ & $*$ & A2 & 1 & A & 2 \\
\hline
\end{tabular}

* Os números finais não haviam sido apurados

** Não disputou competições pelo Campeonato Brasileiro

*** Disputou a seletiva para o Campeonato Brasileiro da série $\mathrm{C}$ 
des transformações desde que os ingleses inventaram o futebol moderno. Inicialmente o futebol moderno era praticado pela elite inglesa, sendo considerado apenas uma atividade cultural típica da burguesia. Na verdade, o surgimento do mercado consumidor de espetáculos esportivos não é um evento histórico, mas um processo mais ligado à popularização de sua prática, conforme Bourdieu (1983). A popularização da prática cria as bases para a consolidação da indústria do espetáculo de futebol, ou seja, cria a demanda ou o gosto de assistir aos jogos de futebol. Para Bourdieu (1983), os esportes ditos populares também funcionam como espetáculos cujo interesse dos consumidores se deve principalmente à participação imaginária que a experiência passada de uma prática real autoriza.

Para Ekelund (1998) foi a partir dos torcedores que todos os outros clientes (TV, patrocinadores, etc.) surgiram. "Quando você avalia economicamente um clube de futebol, o seu valor (ou seja, sua capacidade de geração de receitas) está na força (devoção) e distribuição desses seus clientes principais: quantos torcedores o clube tem? Qual é o retorno de um jogo em termos de audiência (tanto no estádio quanto pela TV)? Quantas pessoas adoram este clube e qual a intensidade desta devoção? Qual é a expansão demográfica dos torcedores? Etc.”

No entanto, apesar de o torcedor representar o consumidor final de espetáculos futebolísticos, existem outros agentes consumidores importantes para os clubes de futebol: os consumidores intermediários. Esses consumidores intermediários utilizam os campeonatos, clubes e jogadores como recursos, a mídia como instrumento de divulgação, a propaganda como negócio, o comércio de mercadorias esportivas, a construção da logomarca de um produto, tendo como "cliente final" de toda essa estrutura o torcedor. Ou seja, o mercado de intermediários, agora como produtores (a TV, a mídia e seus parceiros de negócio), operam para atender ao mercado "consumidor" alvo, no caso do futebol, os torcedores. A Figura 2 ilustra essa estrutura de relacionamento entre mercados para os clubes de futebol.

Como pode ser percebido, existem clientes diferenciados que fazem parte de mercados diferenciados. Resumidamente, então, se tem a seguinte estrutura:

Mercado Produtor de "espetáculos futebolísticos": Organizações de Prática (Clubes) e de Administração do Futebol (Ligas ou Federações e Confederações).

Mercado Consumidor: os torcedores são os consumidores finais (indivíduos e famílias) que compram bens e serviços para seu consumo pessoal. Dentro desse mercado atendido diretamente pelas organizações de futebol observam-se atualmente duas operações básicas: 1) a bilheteria (público que vai ao estádio) que é a operação principal para este tipo de mercado, também denominado mercado consumidor ativo (público que vai ao estádio); o serviço (ou experiência proporcionada pelas atividades) prestado nos estádios teoricamente produz uma utilidade psicológica (ou nutrição psicológica, conforme Taylor, 1998); e 2) o merchandising que é a venda, pelo clube, de produtos com a sua marca; aqui a utilidade representa uma satisfação ligada principalmente à simbologia do produto físico ou serviço. Neste caso, o que o

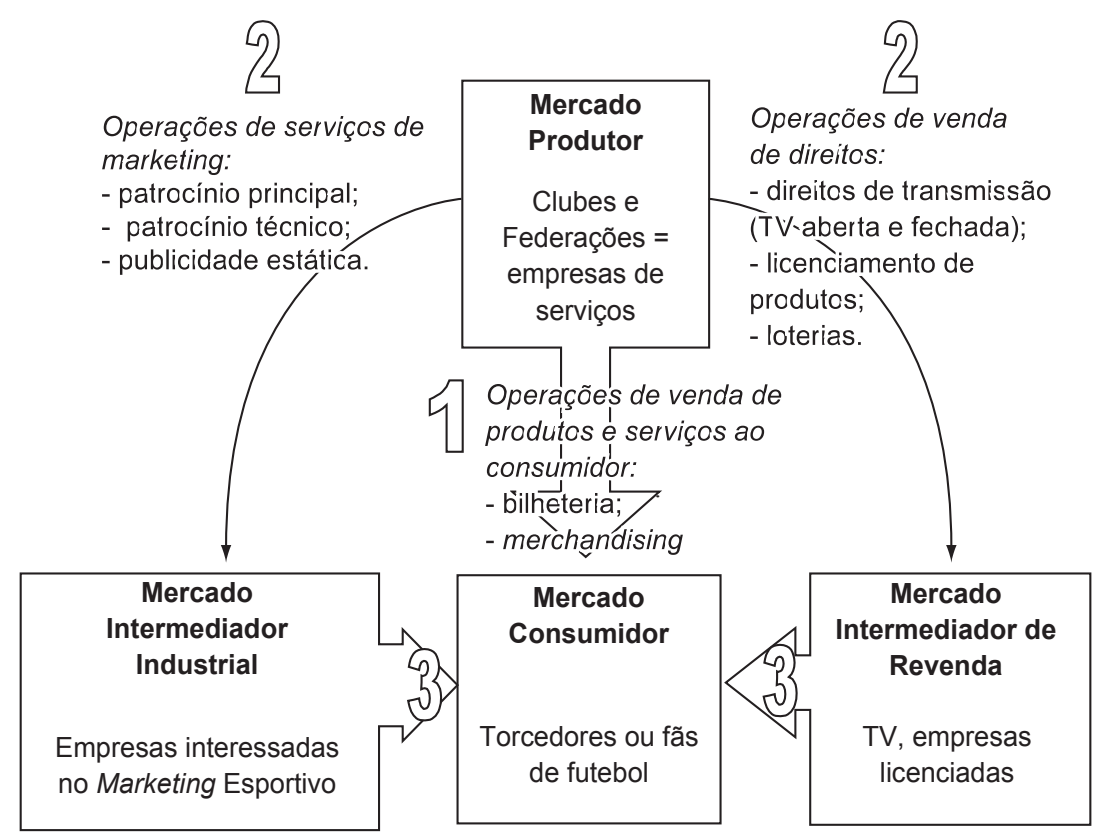

Figura 2. Estrutura Integrada de Mercados para as organizações de futebol - a economia do mercado futebolístico (Fonte: Aidar et al., 2000). 
diferencia do licenciamento de produtos está no fato de que o controle da operação de venda de tais produtos ou serviços é estratégica para as organizações de futebol.

As formas com que os cubes tratam o mercado consumidor variam de clube para clube e de país para país. Os clubes ingleses, obrigados pelo governo britânico a reformarem muitos de seus estádios, após a crescente violência nos estádios no final da década de 90 que culminou com o massacre de torcedores em Hillsborough, são atualmente os clubes que melhor exploram as receitas deste mercado. Nos dias atuais, na Inglaterra, "ir assistir a um jogo de futebol" pode ser o mesmo que ir a um shopping center: a necessidade por segurança, limpeza, locais para estacionamento, hospitalidade, etc, para os clientes, têm sido um fator reconhecido e explorado, visando aumentar a renda para os clubes. Vejamos um comparativo entre três clubes de três países diferentes (Figura 3). Nos exemplos comparativos de três dos maiores detentores de torcida nos seus respectivos países, vemos que para o clube inglês, Manchester United, este mercado significa $65 \%$ de sua receita total. Para o clube italiano, Milan, este mercado significa $40 \%$ e para o clube brasileiro, Flamengo, significa apenas $18 \%$.

Mercado Intermediador: este mercado é análogo ao mercado de intermediários, descrito por Kotler (1995), no sentido de que os clientes desse mercado compram "serviços" (direitos de exploração e transmissão de jogos e serviços de marketing esportivo) tendo em vista "revendê-los" ao mercado de consumo. Ele pode ainda ser dividido em dois outros tipos de mercados: o Intermediador Industrial, para o qual as operações ou atividades de

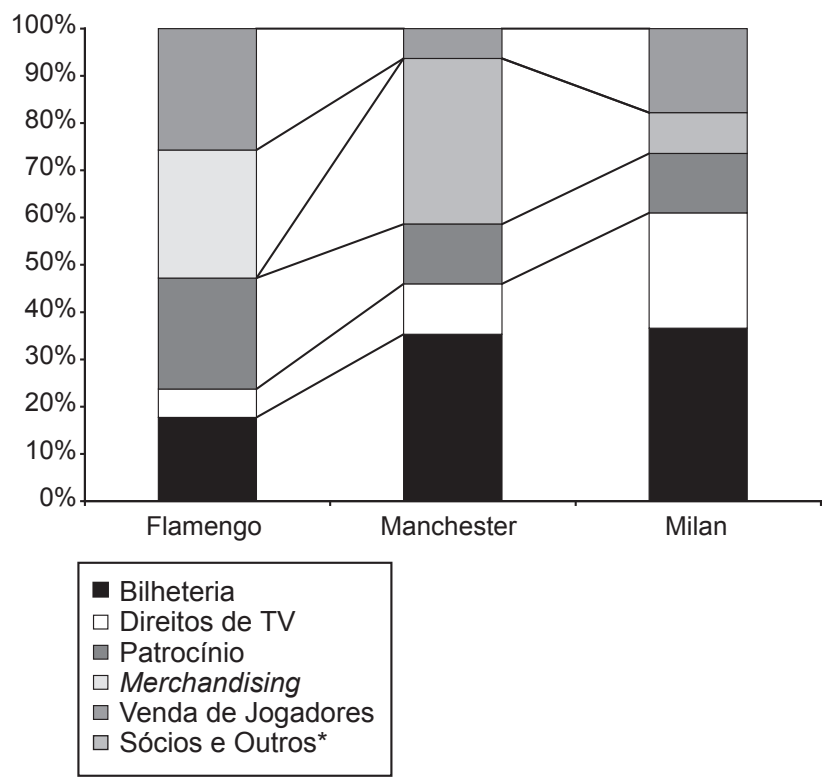

Figura 3. Comparativo da porcentagem de cada tipo de receita gerada por três clubes (Fonte: Booz-allen \& Hamilton, 1999). marketing esportivo prestadas pelas organizações esportivas representam ou produzem uma maneira alternativa de realização de seus objetivos de marketing (promoção, publicidade, exposição na mídia, etc.); e o Intermediador de Revenda, para o qual as operações ou atividades prestadas pelas organizações esportivas (venda de direitos de utilização dos campeonatos e da marca do clube via transmissão dos jogos, via loteria esportiva e via venda de produtos licenciados) representam transações de intangíveis que são utilizados para produzirem novas transações de serviços aos torcedores (transmissão dos jogos via pay-per-view ou via TV aberta, venda de loteria esportiva, venda de produtos licenciados) e demais interessados (venda, pela mídia, de propaganda nos horários/ espaços dos jogos/eventos esportivos).

Ao se observar a Figura 2, nota-se que os dois mercados de intermediários fazem parte da cadeia de produção de usos do espetáculo esportivo. Junto com o que foi chamado de mercado consumidor, esses três mercados podem ser chamados, daqui para frente, de Mercado de Torcedores, pois visam fundamentalmente esses agentes que consomem o espetáculo esportivo. Já o mercado do principal insumo usado neste processo de produção para os clubes será chamado de Mercado de Jogadores. Ele apresenta características diferenciadas dos mercados de recursos humanos de outras indústrias. A análise das leis que regem o mercado de jogadores (o que se costuma chamar aqui no Brasil de "leis do passe" e tudo o mais que decorre das transferências de jogadores entre os times) não será conduzida neste trabalho. O que importa aqui é perceber, conforme Taylor (1998), que os jogadores (ou os contratos / vínculos dos jogadores com os clubes/empresários FIFA) representam ativos intangíveis de alto valor, pois são estes "insumos" que fazem o espetáculo.

Conforme Szymanski e Kuypers (1999), o futebol é um produto (o entretenimento de um jogo de futebol) fornecido por trabalhadores (jogadores e comissão técnica) usando terra (campos), construções (estádios) e equipamento (bolas, chuteiras, etc.) numa competição e por meio de cooperação com os rivais. Essa definição do produto futebol ressalta que o sistema de produção do espetáculo só pode existir por meio da cooperação entre os clubes que competem por títulos esportivos. No jargão econômico, os competidores na indústria esportiva, como a do futebol, são também complementares no processo de produção. Daí surgiu, desde os primórdios do esporte moderno, a necessidade de uma entidade em forma de liga que coordenasse os clubes e se encarregasse das regras.

Pode-se considerar, acrescentando as noções de mercado de jogadores e a de cooperação, e aproveitando a estrutura mostrada na Figura 2, que a estrutura da cadeia produtiva da indústria de futebol pode ser representada pela Figura 4. Portanto, a Figura 4 mostra que os clubes-empresas fazem parte de uma cadeia produtiva com- 
plexa, que tem nos eventos / jogos de futebol o produto principal dessa cadeia.

\section{O negócio futebol para os clubes}

O negócio ou a lógica micro-econômica dos clubesempresas no contexto da indústria do futebol representa o terreno onde as dinâmicas do processo de mudança (ilustradas na Figura 1) acontecem.

A primeira premissa micro-econômica se relaciona à natureza da demanda pelo produto futebol. Neste ponto, a análise de Kim (1997), tratando da direção futura da organização do futebol profissional na área da administração da entrega da qualidade de serviço, se torna útil para a análise da evolução do produto básico dos clubes: o "jogo de futebol".

Ele argumenta que a provisão de serviços esportivos de sucesso requer um entendimento das dimensões da qualidade da entrega do serviço (jogo de futebol) para atender às expectativas do espectador (consumidor ativo): os fatores associados ao resultado do evento (jogo) e os fatores de administração do evento. Enquanto, para os clubes individualmente, os fatores associados ao resultado do evento (principalmente as vitórias do time) sempre foram os principais fatores relacionados à satisfação e ao aumento (a longo prazo) dos chamados torcedores fiéis, a transformação ou a transição no perfil dos espectadores esportivos dentro dos estádios tem aumentado a importância dos fatores associados às condições do estádio, ou seja, ao que Kim (1997) chamou de fatores associados à administração do evento.
Uma outra premissa, que também afeta o desempenho do produto futebol para os clubes, está relacionada à lógica do processo produtivo de suas ofertas: a necessidade de cooperação com os rivais, que leva à necessidade de equilíbrio competitivo numa certa competição esportiva, sendo, portanto, um fator relacionado ao resultado do evento. Como diz o presidente do Manchester United, Martin Edwards, apud Fynn e Guest (1998), a força de um campeonato é a força de seu time mais fraco. Se por vários anos o mesmo time for campeão sem disputa acirrada, o torcedor perderá o interesse pelo futebol. Desta forma, a lógica da concorrência no mercado futebol é diferente da lógica dos outros mercados. Os rivais são peça fundamental para o sucesso do clube individualmente.

Outra questão fundamental, que complementa o pano de fundo micro-econômico para o clube, é a questão do significado de sucesso nessa indústria e os fatores que os explicam.

Definir o que significa sucesso em uma organização depende fundamentalmente da opinião e do poder que cada stakeholder (os principais interessados nos resultados da organização) tem para fazê-lo.

Para o caso dos clubes de futebol, conforme Leoncini (2001), por natureza, eles são organizações que necessitam administrar um trade-off fundamental de desempenho: desempenho esportivo (vitórias) vs. desempenho financeiro (lucros / equilíbrio).

O Desempenho Esportivo é o desempenho do time no campeonato ou competição sendo disputada, que pode ser, de maneira geral, medido pela posição ocupada nesta competição (primeiro lugar, segundo lugar,...). Os fato-

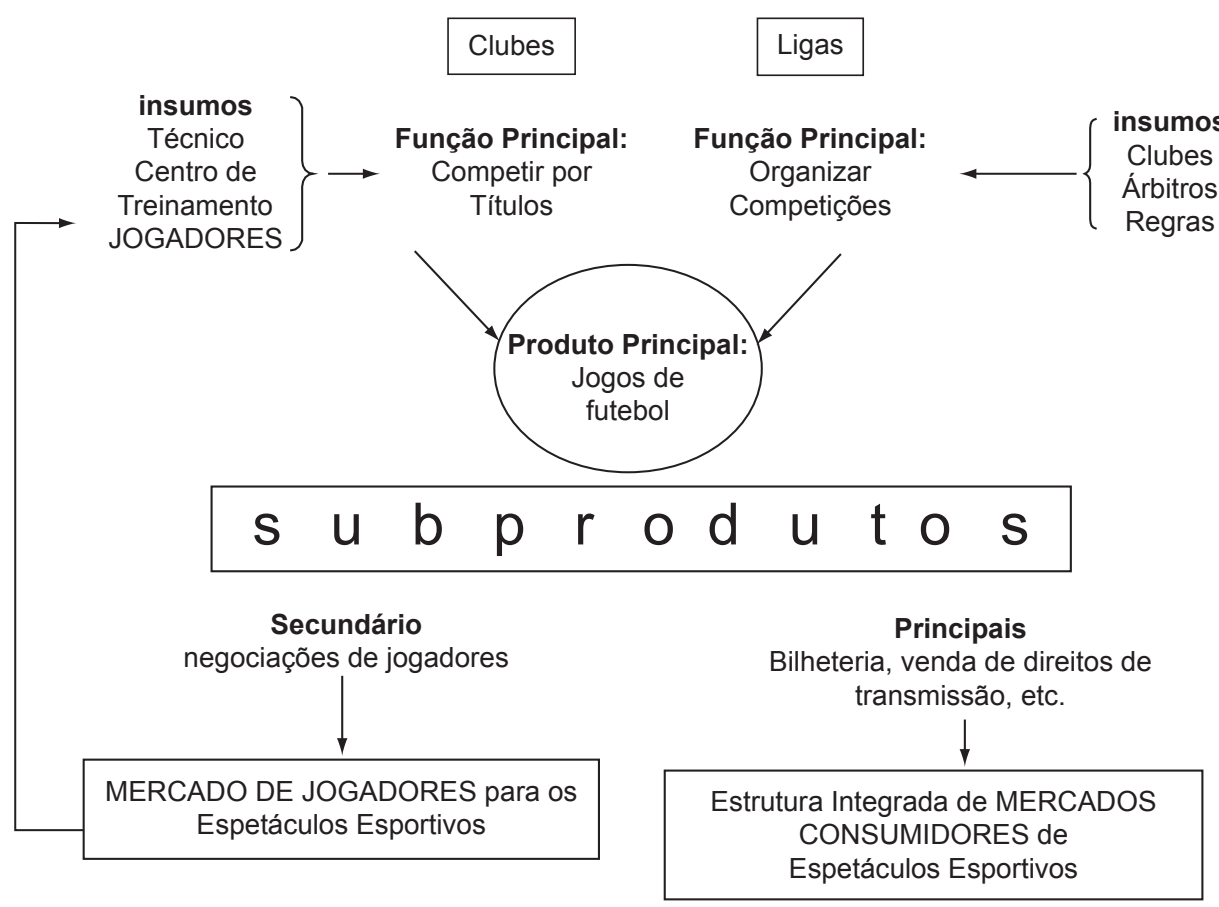

Figura 4. Estrutura da Cadeia Produtiva na Indústria de Futebol (Fonte: Elaborada pelos autores). 
res internos ao clube que o influenciam se restringem à competência do seu departamento técnico (treinadores, preparadores físicos, jogadores, etc.). O Lucro operacional ou desempenho financeiro do clube em determinado período é a diferença entre a soma das receitas geradas pelo mercado de torcedores, e a soma de suas despesas com salários de jogadores, estádios, equipamentos, enfim, com seus recursos fundamentais. As operações de compra e venda de jogadores podem ser consideradas operações de investimento.

Mas como tal desempenho financeiro pode ser influenciado? Para a análise da equação do lucro do negócio futebol do ponto de vista dos clubes, é necessário definir o clube como um agente econômico gerador de custos e receitas:

- Custos Principais - Gasto com salários: o gasto do clube com salários, principalmente do departamento técnico (treinadores, jogadores, preparadores, psicólogos, etc.). Esses gastos representam a maior parte das despesas de um clube de futebol (Jefferson Slack, em reportagem na Gazeta Mercantil - Caderno Empresas \& Carreiras, sexta-feira, 27, e Sábado, 28 de Agosto de 1999 -, vicepresidente da The Muller Sports Group, empresa que cuidava das Políticas Estratégicas da parceria Corinthians / Hicks Muse, afirmou que os custos do futebol se restringem basicamente aos gastos com salários, contratações e prêmios dos profissionais); e

- Receitas geradas: total de receitas geradas pelo clube por meio da exploração do mercado de torcedores (venda de direitos de TV, bilheteria, patrocínio de camisa, patrocínio de material esportivo, e venda de produtos licenciados).

Esses fatores representam as variáveis básicas que compõem a equação do lucro para um clube. Ou seja, o resultado do clube em cada fator ou variável mencionada acima determinará, em última instância, seu resultado financeiro. Assim, a questão que se coloca a seguir é: como tais variáveis se relacionam e que fatores são críticos para o sucesso financeiro de um clube?

Após concluírem que o lucro nunca foi consistente para os clubes ingleses, Szymanski e Kuypers (1999) procuraram analisar como a busca pelo desempenho esportivo, outro propósito fundamental de um clube, poderia estar influenciando a lógica do negócio. Para isso eles analisaram dois relacionamentos fundamentais. $\mathrm{O}$ primeiro olhou o desempenho esportivo (medido pela posição ao final da Competição) em relação ao gasto do clube com salários de jogadores. O segundo explorou o relacionamento entre geração de receitas e desempenho esportivo.

Tais estudos sugerem a existência de correlações significativas e diretamente proporcionais entre desempenho esportivo e gasto com salários e entre desempenho esportivo e geração de receitas no mercado de torcedores. Em outras palavras, isto quer dizer que, embora um time "caro" nem sempre vença um time "barato", a longo pra- zo e a médio, o relacionamento entre gasto com salários e desempenho no Campeonato é bastante significativo. Do mesmo modo, times mais vitoriosos a longo prazo provavelmente atrairão maiores receitas. Tradicionalmente, esta característica do negócio futebol tem feito com que a maioria dos dirigentes invista recursos significativos na montagem de um bom time, para que o resultado esportivo venha acompanhado do aumento de suas receitas. O que aconteceu no Brasil foi que a única preocupação dos dirigentes sempre foi com a montagem desse grande elenco, com despesas (salários) e investimentos (contratações) exorbitantes e pouca preocupação com a geração de receitas que tal time pode gerar no mercado de torcedores. Logo, o desempenho esportivo, a exploração eficaz do mercado de torcedores e o controle da folha salarial são fatores fundamentais para explicar a lógica do negócio para um clube de futebol.

Considerando-se o lucro para um clube como a parcela que sobra das receitas (provenientes do mercado de "torcedores") após se apurarem os custos relacionados às suas atividades principais (proveniente dos gastos dos clubes com os fatores de mercado - manutenção de estádios, pessoal de contato com clientes, etc. - e com os fatores esportivos - jogadores, técnicos, preparadores físicos, etc.), a Figura 5 pode ser usada para ilustrar a lógica do negócio para um clube de futebol.

\section{Escolhas estratégicas e estrutura de operações dos clubes}

Depois das análises das condicionantes estruturais da indústria de futebol, que formam as regras do jogo competitivo para os clubes de futebol, estes entendidos como empresas de serviço, a abordagem de Heskett et al. (1990) sobre gestão de serviços pode ser usada para entender a concepção do modelo de gestão estratégica dessas empresas diferenciadas de serviços, ou seja, suas escolhas estratégicas e estrutura de operações.

Conforme Heskett et al. (1990), a visão estratégica de serviços é a forma abrangente e sistêmica com que empresas bem sucedidas vêem e conduzem seus negócios. Essas empresas, chamadas de revolucionárias pelo autor, definem os elementos básicos da visão estratégica: mercados-alvo, conceito de serviço, estratégia operacional e sistema de prestação de serviço. E integram esses elementos, o que significa a formação de competências dentro da empresa, já que implicam tomadas de decisão que respondem a questões do tipo "como fazer".

Tal integração ou desenvolvimento de competência se dá em três níveis organizacionais: o primeiro, no nível das estratégias competitivas, por meio do posicionamento estratégico que é o processo pelo qual todos os aspectos da visão estratégica (mercados-alvo, conceito do serviço, estratégias de operações e sistemas de prestação 


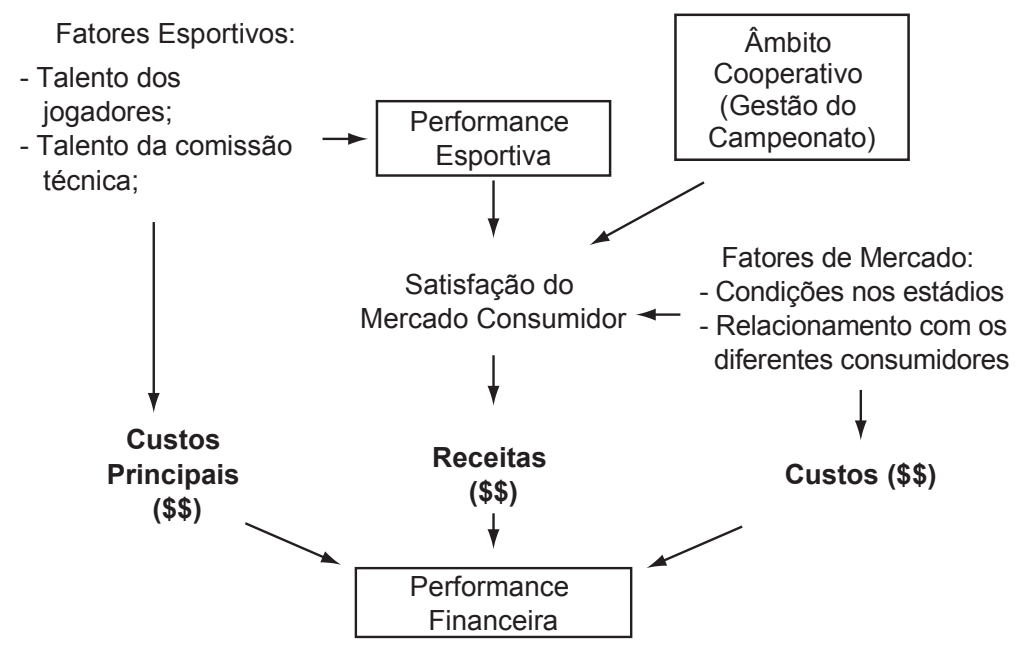

Figura 5. A equação do lucro para os clubes de futebol (Fonte: adaptado de Leoncini, 2001).

de serviços) são projetados e gerenciados em relação às necessidades dos consumidores e às possibilidades dos concorrentes. Assim, o posicionamento estratégico do clube implica, em última instância, a escolha do mercado em que ele irá competir. Como foi descrito anteriormente, existem dois tipos básicos de mercados operando na indústria de futebol: o mercado de torcedores e o de jogadores. A Figura 3 mostrou que os clubes brasileiros, como o Flamengo, detentor da maior torcida no Brasil, está mais voltado ao mercado de jogadores, que representa cerca de $30 \%$ de sua receita, contra 5\% do Manchester.

O segundo, no nível da formulação da estratégia de negócio, é um processo de aprendizagem que busca identificar os parâmetros determinantes do lucro que compõem a estratégia de operações, por meio de um conceito de alavancagem de valor sobre custos: como alcançar alta qualidade (esta entendida como resultados esperados pelos consumidores) a baixo custo? Nesse caso, as leis do negócio futebol mostraram a importância do desempenho esportivo (posição do time na competição), dos fatores ligados à administração dos eventos (chamados de fatores de serviço ao torcedor) e do gasto com a folha salarial do time. Logicamente, a escolha do mercado-alvo determinará que fatores devem ser privilegiados.

E o terceiro, no nível da integração entre as estratégias e o sistema operacional, é um conjunto de competências funcionais que buscam tornar coerente a estratégia e o sistema de prestação de serviço partindo-se da premissa de que este é conceituado como uma oportunidade de aumentar e controlar a qualidade dos resultados obtidos pelos clientes: como selecionar, desenvolver, motivar, controlar o pessoal e projetar as instalações, os equipamentos, os procedimentos, etc? Nesse caso, a eleição e o desenvolvimento das competências principais dependerá das escolhas estratégicas que o clube faz. Ao mesmo tempo, tais desenvolvimentos fazem emergir novas estratégias, num círculo virtuoso que pode variar de um clube para outro. No caso do Manchester United que, segundo seu diretor Freedman, revolucionou a lucratividade do clube depois de focalizar seus serviços no mercado de torcedores, os investimentos nas instalações do estádio visando facilitar e melhorar a qualidade do serviço ao torcedor bem como os investimentos (contratações) e despesas (salários) com jogadores para manter um time vencedor, são ações na direção de um sistema operacional adequado à estratégia do negócio futebol para o clube.

Com relação à nova visão estratégica para orientar o negócio, no caso do Flamengo, a nova organização resultante da parceria assume que o mercado-alvo do negócio futebol passa a ser o mercado de torcedores e sócios do clube. O conceito de serviço, em termos de resultados esperados por este mercado está relacionado à atividade do lazer e entretenimento, com um forte componente emocional (paixão pelo clube) que envolve este tipo de cliente. Neste caso, tais resultados esperados estão ligados à experiência diferenciada que o jogo de futebol pode proporcionar, tais como emoção, conforto, alívio de estresse, vitória do time, etc.

A estratégia do departamento técnico da parceria busca dar ênfase à definição de metas ambiciosas para as aspirações esportivas do clube (conquistar títulos). Na gestão do Marketing pela ISL, a estratégia é fornecer um tratamento diferenciado e focalizado na melhoria dos serviços (fatores mercadológicos) aos torcedores e sócios nos estádios e clubes. A alavancagem do lucro pela organização começa pelo controle sobre o gasto com a folha salarial do time, teoricamente praticado por meio da imposição pelo parceiro de um orçamento anual fechado (na prática, tal estratégia não funcionou, pois o clube permaneceu com independência para administrar o dinheiro que o parceiro pagava para administrar a marca Flamengo). Com relação à integração "estratégia - sistema de presta- 
ção dos serviços", ou seja, ao que chamamos de estruturas ou sistemas de operações do clube, tais questões não puderam ser exploradas a contento.

No caso do São Caetano, a nova organização assume que o mercado-alvo do negócio futebol passa a ser o mercado de jogadores a médio prazo. $\mathrm{O}$ conceito de serviço, em termos de resultados esperados pelo mercado-alvo está relacionado à atividade de desenvolvimento de talentos, ou seja, uma atividade típica de capacitação de recursos humanos. Neste caso, o bom desempenho esportivo do time caracteriza o conceito de serviço, pois o desempenho da equipe potencializa e mostra as competências individuais dos jogadores, estes que são os próprios "objetos" de desejo do mercado-alvo.

A estratégia do departamento técnico busca a ascensão esportiva às principais divisões do futebol brasileiro, sendo o desempenho esportivo considerado o principal fator para o oferecimento do serviço prometido. Na gestão do Marketing pela Datha, a estratégia é a ênfase no marketing esportivo para auxiliar na manutenção de um equilíbrio financeiro que garanta a operação do negócio futebol (despesas com categorias de base e do departamento profissional). A alavancagem do lucro ou do equilíbrio financeiro pela organização começa pelo controle sobre o gasto com a folha salarial do time. Há também uma preocupação com as formas de tratamento e de recompensa dadas aos jogadores (pagamento em dia e rigorosamente de acordo com o prometido), o que ajuda a melhorar o comprometimento dos jogadores com as metas de desempenho esportivo. Além disso, o planejamento a longo prazo por parte da diretoria permite que se verifiquem situações mais estáveis e seguras de trabalho (manutenção de um time base, de um treinador por tempo maior que a média dos outros clubes, etc.). Com relação à integração "estratégia - sistema de prestação dos serviços", ou seja, ao que chamamos de estruturas ou sistemas de operações do clube, tais questões não puderam ser exploradas a contento. A Tabela 2 ilustra os números da parceria até 2000 e mostra também como receitas e despesas são controladas.

\section{Conclusões e recomendações de pesquisa}

O resultado deste trabalho nos permite uma visão mais clara do negócio futebol como um sistema de produção para os clubes, apesar das poucas informações esclarecedoras sobre o funcionamento das operações de negócio, como os números gerados por cada sistema de operação para um clube (bilheteria, patrocínio principal, negociação de jogadores, etc.). Além disso, permite que se perceba as principais condicionantes estratégicas da indústria de futebol que influenciam a concepção do modelo de gestão de um clube de futebol atualmente.
Os dois estudos de caso realizados por Leoncini em 2000 corroboraram tais percepções e mostraram o caráter incipiente da mudança na gestão de clubes de futebol no Brasil, o que não impediu a descoberta de alguns princípios de gestão já consolidados (Ver Tabela 3). Porém, tendo em vista os objetivos iniciais deste artigo, algumas considerações finais sobre as variáveis e conceitos desenvolvidos se fazem necessárias para uma apreciação mais sintética dos resultados desse trabalho.

A estrutura e a lógica do negócio futebol representam o pano de fundo micro-econômico para a atuação dos clubes de futebol e são condicionantes estruturais diferenciadas e mais complexas do que a de outros setores econômicos mais tradicionais. Por exemplo, a caracterização da cadeia de produção da indústria de futebol, com seus vários agentes interdependentes e com interesses muitas vezes conflitantes, representa uma das principais condicionantes dessa indústria. Se, por um lado, os torcedores ou o mercado de torcedores gostariam que alguns jogadores permanecessem no "seu" clube por bastante tempo, por outro, empresários de jogadores lucrariam mais a curto prazo com a transferência deste mesmo jogador para outro clube. Assim, o estabelecimento de políticas e diretrizes a longo prazo dentro da indústria estará sempre condicionado por tais características. Outro aspecto importante deste cenário é a importância do âmbito cooperativo dos clubes de futebol.

Dentro deste contexto, as principais mudanças interempresariais ocorridas até agora na indústria se resumiram a mudanças horizontais, resultando em parcerias entre clubes e empresas investidoras que visavam principalmente tornar o negócio dos clubes lucrativo pela complementaridade de competências e aumento de receitas (Corinthians e Hicks Muse, Flamengo e ISL, Cruzeiro e Hicks, etc.). Contudo, apesar de algumas dessas mudanças apontarem para a consolidação da indústria do futebol como uma indústria de entretenimento, cujo principal produto é o espetáculo futebolístico e não o "jogador brasileiro", mudanças verticais e estruturais ainda são necessárias, como a consolidação desta visão estratégica para o negócio futebol no Brasil, dirigida por uma cooperação efetiva entre clubes.

Já as principais variáveis e premissas de gestão estratégica para um clube de futebol puderam ser observadas nos dois estudos de caso. A primeira, qual seja a própria visão estratégica para o negócio do clube, indica que os funcionamentos paralelos dos mercados de torcedores e jogadores obrigam os clubes a priorizarem um em detrimento do outro. Esta priorização direciona então os esforços do clube para o estabelecimento de metas financeiras e esportivas e o desenvolvimento de competências organizacionais. Por exemplo, no caso do Flamengo, o lucro passa a ser um de seus principais objetivos estratégicos. Assim, o bom desempenho esportivo e a melhoria 
Tabela 3. O processo de mudança no modelo de gestão de dois clubes brasileiros (Fonte: adaptado de Leoncini, 2001).

\section{Flamengo São Caetano}

\begin{tabular}{|c|c|c|c|}
\hline \multirow[t]{3}{*}{$\begin{array}{l}\text { Dinâmicas Internas à Indús- } \\
\text { tria do Futebol }\end{array}$} & Dinâmicas de Contexto & $\begin{array}{l}\text { Ineficácia Esportiva e Finan- } \\
\text { ceira dos antigos dirigentes; }\end{array}$ & $\begin{array}{l}\text { Vontade Política de Profissiona- } \\
\text { lizar a gestão e de tornar o clube } \\
\text { vitorioso nacionalmente }\end{array}$ \\
\hline & $\begin{array}{l}\text { Dinâmicas Interempresariais } \\
\text { (Novas Parcerias) }\end{array}$ & $\begin{array}{l}\text { Horizontal (complem. de } \\
\text { competências): licencia- } \\
\text { mento da marca pelo novo } \\
\text { parceiro }\end{array}$ & $\begin{array}{l}\text { Horizontal (complem. de } \\
\text { competências): assinatura de um } \\
\text { contrato de co-gestão }\end{array}$ \\
\hline & $\begin{array}{l}\text { Novo Posicionamento Estratégi- } \\
\text { co (mercado-alvo) }\end{array}$ & $\begin{array}{l}\text { Mercado de torcedores e } \\
\text { sócios: o evento-jogo de } \\
\text { futebol é considerado um } \\
\text { serviço de lazer e entreteni- } \\
\text { mento para o mercado }\end{array}$ & $\begin{array}{l}\text { Mercado de jogadores: o evento- } \\
\text { jogo de futebol é considerado } \\
\text { um mecanismo para desenvolver } \\
\text { talentos }\end{array}$ \\
\hline Escolhas Estratégicas & $\begin{array}{l}\text { Fatores Críticos para o sucesso } \\
\text { do Negócio }\end{array}$ & $\begin{array}{l}\text { O desempenho esportivo } \\
\text { (conquistar títulos), o foco } \\
\text { em serviços, e o controle } \\
\text { sobre a folha salarial são } \\
\text { elementos chave para a } \\
\text { lucratividade }\end{array}$ & $\begin{array}{l}\text { O desempenho esportivo (con- } \\
\text { quistar títulos) e o controle sobre } \\
\text { a folha salarial são elementos } \\
\text { chave para a lucratividade/equi- } \\
\text { líbrio }\end{array}$ \\
\hline \multirow[t]{2}{*}{$\begin{array}{l}\text { Estruturas ou Sistemas de } \\
\text { Operações }\end{array}$} & $\begin{array}{l}\text { Voltadas para o Mercado de } \\
\text { Torcedores }\end{array}$ & - & - \\
\hline & $\begin{array}{l}\text { Voltadas para o Mercado de } \\
\text { Jogadores }\end{array}$ & - & - \\
\hline
\end{tabular}

das condições dos serviços aos torcedores passam a ser fatores críticos para a satisfação do mercado-alvo e conseqüentemente para a melhoria na geração de receitas. Além disso, o controle da folha salarial é outro aspecto importante para a realização do lucro esperado.

Do ponto de vista do desenvolvimento de novas pesquisas relacionadas ao entendimento do negócio futebol e à gestão estratégica de clubes de futebol, também é evi- dente o enorme campo que se vislumbra para esse novo setor da indústria do entretenimento como, por exemplo, nas áreas de gestão econômico-financeira, marketing de serviços, etc. Já no campo das ciências do esporte, notase que a questão do desempenho esportivo assume papel preponderante dentro da lógica do negócio futebol e também deve merecer atenção cada vez maior de pesquisadores e profissionais.

\section{Referências Bibliográficas}

AIDAR, A. C. K.; LEONCINI, M. P.; OLIVEIRA, J. J. A nova gestão do futebol. Rio de Janeiro: Editora FGV, 2000.

BOURDIEU, P. Questões de Sociologia. Rio de Janeiro, Ed. Marco Zero Ltda., 1983.

EKELUND, P. A Rentabilidade das Associações de Times de Futebol: os exemplos das Ligas de Futebol da Itália e da Inglaterra. Texto apresentado no 1o. Congresso Internacional EAESP de Gestão de Esportes organizado pela Fundação Getúlio Vargas. São Paulo, 1998.

FLEURY, A.; FLEURY, M. T. L. Estratégias empresariais e formação de competências: um quebra-cabeça caleidoscópico da indústria brasileira. - São Paulo : Atlas, 2000.

FYNN, A.; GUEST, L. For love or money: Manchester
United and England - the business of winning? Ed. Macmillan Publishers Ltd, London, 1998.

HESKETT, J.; SASSER Jr., W.; HART, C. Service breakthroughs - changing the rules of the game. New York: The Free Press, 1990.

KIM, J. H. Spectator satisfaction at professional soccer games in the Republic of Korea. Daphne, Alabama. United States Sports Academy (Doctor of Education). p. 78, 1997.

KOTLER, P. Princípios de Marketing. Ed. Atlas, São Paulo, 1995.

LEONCINI, M. P. Entendendo o negócio futebol: um estudo sobre a transformação do modelo de gestão estratégica nos clubes de futebol. Tese (Doutorado), São Paulo. Escola Politécnica, Universidade de São Paulo, 2001. 
MOTTA, F. C. P.; PEREIRA, L. C. B. Introdução à Organização Burocrática. Ed. Brasiliense, São Paul, 1980.

PRIMEIRO CONGRESSO INTERNACIONAL EAESP DE GESTÃO DE ESPORTES. São Paulo: Fundação Getúlio Vargas, 1998.

RELATÓRIO FINAL DO PLANO DE MODERNIZAÇÃO DO FUTEBOL BRASILEIRO. Rio de Janeiro : Fundação Getúlio Vargas e Confederação Brasileira de Futebol, 2000.

BOOZ-ALLEN \& HAMILTON. Relatórios Anuais; Publicações; Análises, 1999.

SZYMANSKI, S.; KUYPERS, T. Winners and Losers - The
Business Strategy of Football. London: Viking, 1999.

TAYLOR, R. As dimensões sociais do relacionamento comercial entre os clubes de futebol e suas comunidades. Texto apresentado no 1o. Congresso Internacional EAESP de Gestão de Esportes organizado pela Fundação Getúlio Vargas. São Paulo, 1998.

YIN, R. Case study research: design and methods. Sage Publications, Califórnia, 1994.

ZARIFIAN, P.; SALERNO, M. S. Organização e produção industrial de serviços. Boletim Técnico da Escola Politécnica da USP, Departamento de Engenharia de Produção, BT/PRO/041; São Paulo, EPUSP, 7p., 1997

\title{
SOCCER SEEN AS A BUSINESS: AN EXPLORATORY STUDY
}

\begin{abstract}
This paper considers soccer clubs as operational systems, and proposes a model to analyze the process of professionalization in soccer club management. Despite their importance in this process, the model does not encompass political variables, focusing, instead, on concepts of systemic learning to understand the organizational changes. The model's theoretical contribution lies in identifying the main structural characteristics of the soccer industry, particularly those of a productive and micro-economic nature, and in presenting some management policies and principles applicable to soccer clubs as service firms. A case-based research methodology is used to identify management principles currently in use and to test the model's validity.
\end{abstract}

Keywords: soccer industry, organizational changes, strategic choices, service management. 